\title{
A review of 50 consecutive cytology cell block preparations in a large general hospital
}

\author{
Frederick Mayall, Bridget Chang, Ann Darlington
}

\begin{abstract}
Aims-To review consecutive cell block preparations of cytological specimens in a large general hospital.

Methods-50 cell blocks were made over an 18 month period in which about 1900 fine needle aspirations (FNAs) were performed. The aspirator was a cytologist or, for image guided FNAs, a radiologist with a cytologist at hand to collect the specimen. Forty eight cell blocks were from FNAs and two were from serous fluids.

Results-The cellularity of the cell blocks was inadequate in only four preparations. The main motive for making cell blocks was to obtain tissue for immunohistochemistry. This was performed on 28 cases and a total of 107 immunostained sections were produced. The most common diagnostic dilemma was between carcinoma and melanoma, and the second most common between carcinoma and lymphoma. Consequently cytokeratin, S-100, and LCA were the most frequently used antibodies. At least one of these three antibodies was positive in 17 cases. Five cases were immunostained only for prognostic breast markers.

Conclusions-The use of cell block immunohistochemistry is a reliable and technically unsophisticated aid in the cytological examination of tumours other than lymphomas. Success depends on having highly experienced aspirators that reliably obtain sufficiently cellular material. $(\mathcal{O}$ Clin Pathol 1997;50:985-990)
\end{abstract}

Accepted for publication 2 September 1997

Department of Pathology, Waikato New Zealand

Dr Mayall, Department of Pathology, Waikato Hospital, Private Bag 3200, Hamilton, New Zealand; email: mayallf@hwl.co.nz

Table 1 Primary antibodies. Their sources, dilutions, and enhancement methods

\begin{tabular}{llll}
\hline Antibody & Source & Dilution & Enhancement \\
\hline Cytokeratin (CAM 5.2) & Becton Dickinson & Prediluted & Microwave \\
S100 & Dako & $1 / 1500$ & Microwave \\
Carcinoembryonic antigen (CEA) & Dako & $1 / 200$ & Microwave \\
Ber EP4 & Dako & $1 / 100$ & Trypsin \\
Prostate specific antigen (PSA) & Dako & $1 / 30$ & Microwave \\
HMB-45 & Dako & $1 / 25$ & Microwave \\
Leucocyte common antigen (LCA) & Dako & $1 / 400$ & Microwave \\
CD20 & Dako & $1 / 200$ & Microwave \\
CD43 & Dako & $1 / 200$ & Microwave \\
Kappa light chain (K) & Novocastra & $1 / 100$ & Trypsin \\
Lambda light chain (L) & Dako & $1 / 50$ & Microwave \\
p53 & Dako & $1 / 25$ & None \& microwave \\
Oestrogen receptor (ER) & Novocastra & $1 / 50$ & Microwave \\
Progesterone receptor (PR) & Novocastra & $1 / 40$ & Microwave \\
c-erb-B2 & Dako & $1 / 900$ & Microwave \\
Thyroglobulin (TG) & Dako & $1 / 100$ & Microwave \\
$\alpha$ Feto protein ( $\alpha$ FP) & Dako & $1 / 500$ & Microwave \\
Desmin & Dako & $1 / 400$ & Microwave \\
Smooth muscle actin (SMA) & Dako & $1 / 40$ & Microwave \\
CD34 & Novocastra & $1 / 25$ & Microwave \\
Factor VIII (F VIII) & Dako & $1 / 1000$ & Microwave \\
\hline
\end{tabular}

Becton Dickinson, Mountain View, California, USA; Dako, High Wycombe, Bucks, UK, Novocastra, Newcastle upon Tyne, UK
Keywords: cell block; immunohistochemistry; fine needle aspiration cytology; audit

Cytology cell blocks are made by centrifuging cytology specimens to form solid pellets. Paraffin wax embedded sections can be cut for haematoxylin and eosin histology and special stains, including immunohistochemistry. This study reviewed 50 consecutive cell block preparations of cytological specimens in a large general hospital.

\section{Patients and methods}

The vast majority of cell block specimens were obtained from fine needle aspirations (FNAs). These were performed as part of a near-patient rapid diagnosis FNA service. A second FNA was used to collect the specimen for the cell block after the initial diagnosis had been made on the first specimen. The image guided FNAs (17 cases) were performed by a consultant radiologist with a cytologist at hand to collect the specimen. A variety of needles was used depending on the site. The manually guided FNAs (31 cases) were performed with a 23 gauge $3.75 \mathrm{~cm}$ needle using a "needle only" technique and the operator was always a consultant pathologist with a special interest in FNA cytopathology. Maximum material was collected by extensive agitation of the needle in the lesion. Ten per cent formal saline was drawn up though the needle into an attached syringe and then gently ejected back into a specimen container.

\section{CELL BLOCKS}

Serous fluids were prepared by centrifuging at $1270 \times g$ for seven minutes, discarding the supernatant, and resuspending in formalin. After at least an hour of fixation the suspension of the FNA specimen in formalin or the resuspension of the serous fluid was centrifuged at $1270 \times g$ for seven minutes. The supernatant formalin was decanted off. The deposit was resuspended in molten $0.9 \%$ agar at $50^{\circ} \mathrm{C}$ and quickly placed in a centrifuge again. It was spun at $1270 \times g$ for two minutes and then refrigerated at $4^{\circ} \mathrm{C}$ for 30 minutes to harden the agar. The excess agar was trimmed to leave a cell button. This was wrapped in tissue paper and placed in a plastic cassette for paraffin processing as for a routine surgical biopsy specimen. A haematoxylin and eosin stained section was cut from each cell block and examined. Any further stains were then requested and performed. 


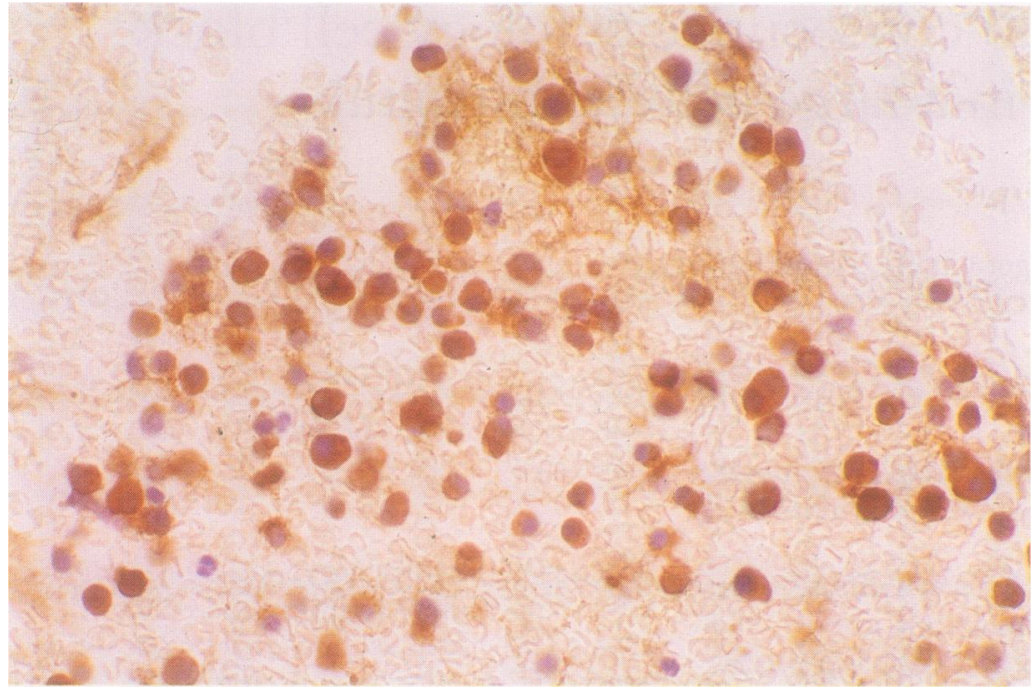

Figure 1 A cell block section from a spinal myeloma deposit showing strong immunostaining for lambda. There was no positivity for kappa.

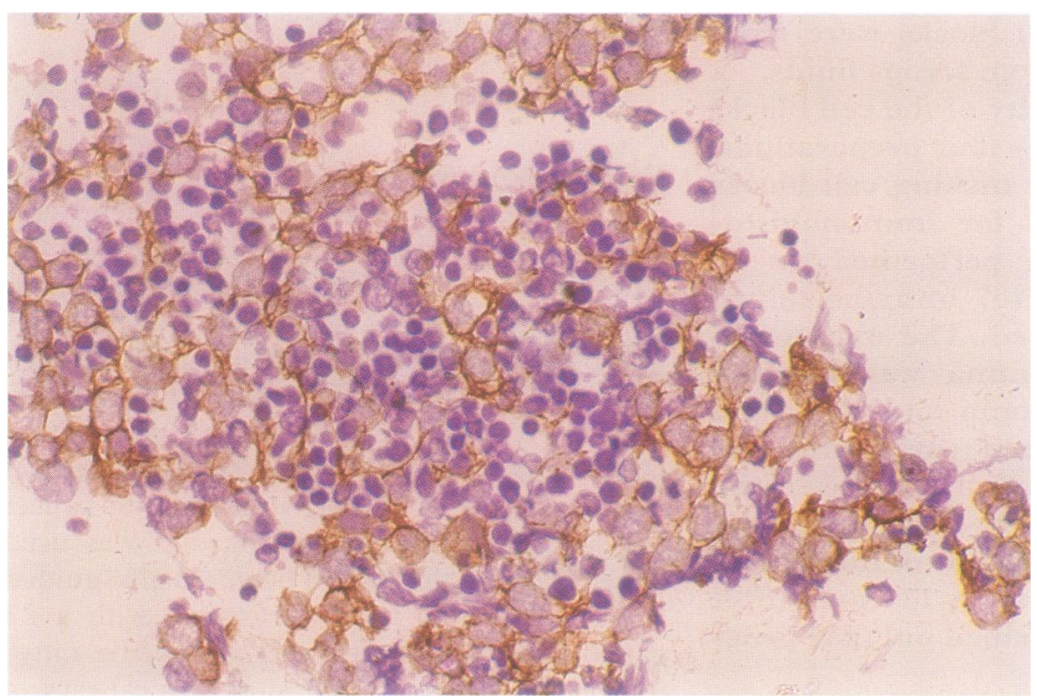

Figure $2 A$ cell block section of a thymoma showing immunostaining for cytokeratin (CAM 5.2) in the epithelial cells but not in the smaller lymphocytes.

\section{IMMUNOHISTOCHEMISTRY}

Immunohistochemistry was performed on $3 \mu \mathrm{m}$ paraffin sections cut on to APES coated slides. Microwave pretreatment was in citrate buffer at $\mathrm{pH} 6$ for 10 minutes at boiling temperature. The sources, dilutions, and incubation times of the primary antibodies are shown in table 1 . The incubation time for the primary antibodies was 10 minutes at room temperature. The sections were then developed using a streptavidin-biotin-immunoperoxidase kit (Dako, High Wycombe, Bucks, UK). The chromogen was DAB.

\section{Results}

The results are displayed in table 2 . These 50 cell blocks were from an 18 month period in which about 1900 FNAs were performed. Forty eight of the 50 cases were FNAs and two were serous fluid specimens. Seventeen of the FNAs were image guided. Most of these were computed tomography guided. Some were fluoroscopically guided FNAs of lung, and a few were ultrasound guided FNAs of the neck.

The cell blocks contained sufficient cells in 46 cases. In 18 cases the cell blocks were not used for immunohistochemistry. In most of these the motive for taking the cell block had been to collect material for immunohistochemistry but then a confident diagnosis was made from conventional cytology alone and immunostaining was not performed. In a few cases, in particular some possible small cell carcinomas of the lung, the cell blocks were taken to see the haematoxylin and eosin stained histology of the cells.

Immunostaining was performed in 28 cases. A total of 107 sections were immunostained and in only one (case 38 ) were there insufficient cells. None of these sections was inadequate for any other reason. The two most common diagnostic dilemmas for which immunostaining was employed were between carcinoma and melanoma (10 cases) and between carcinoma and lymphoma (nine cases). Cell block immunohistochemistry was performed solely for breast carcinoma prognostic markers (oestrogen receptor, progesterone receptor, and c-erb-B2) in five cases. Breast markers were performed in conjunction with other immunostains in five further cases.

Cytokeratin was used for 21 of the 28 immunostained cases, S-100 on 11 cases, and leucocyte common antigen (LCA) for nine cases. At least one of these three antibodies was positive for 17 cases. Cytokeratin was used on every occasion that one or both of the other two were used. These three antibodies were used far more than any others except for prognostic breast markers (10 cases). The largest number of immunostains done on one cell block was eight. Twenty one different antibodies were used in total; seven being used only once. A diastase periodic acid-Schiff stain was also used on two cases.

Cell blocks were not usually performed on tumours that appeared to be lymphoid in the smears as the material obtained from the second aspirate was usually used for immunolabelled flow cytometry instead. There were 24 FNA samples taken for lymphoid marker flow cytometry during the period studied. Consequently the cell block cases for which lymphoid immunostains were positive tended to be unusual lymphoid neoplasms or other tumours. These included a myeloma deposit in the spine (fig 1), a high grade T cell lymphoma, a thymoma (fig 2), and a high grade B cell lymphoma.

Cell blocks were taken from six possible small cell carcinomas. In three of these cases only haematoxylin and eosin stained sections were cut but immunostains for cytokeratin and LCA were performed on three, and were positive for cytokeratin in two. The third (case 38) had insufficient cells in the immunostained sections. In the other 27 cases the results of the immunohistochemistry either confirmed the cytological diagnosis that had been suggested in the provisional report issued at the time of the aspirate or, in a few cases, indicated the correct diagnosis from a choice of two or more that were being considered. One example of the latter was lymphoma versus thymoma in case 37. The immunolabelled flow cytometry for lymphoid markers showed this tumour to be composed almost exclusively of $\mathrm{T}$ cells but the 


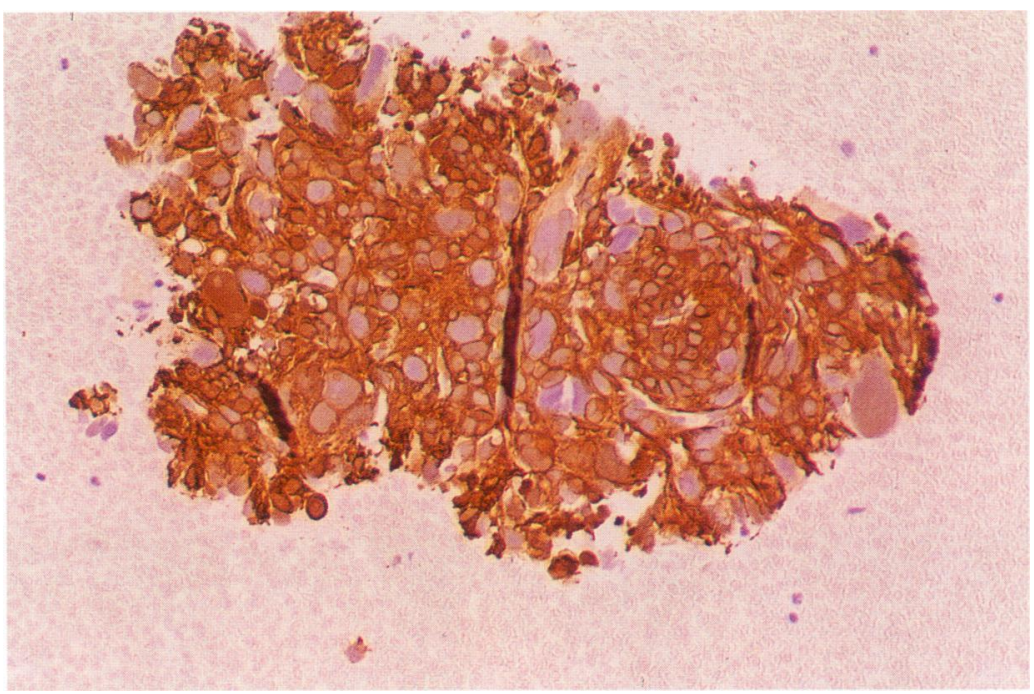

Figure 3 A cell block section of a leiomyosarcoma showing immunostaining for smooth muscle actin. examining the cell blocks. ${ }^{2}$ This was not our experience but our study was fundamentally different in that we examined the cytology specimens immediately and if they did not contain sufficient material for a definite diagnosis the FNA was repeated and more smears examined. In the study by Brown et al the cytology smears and the material for the cell blocks seem to have been sent away to the laboratory for examination and there was no opportunity to repeat the aspirate if the smears were not diagnostic. A study by Flint on cytology and cell blocks from 111 bronchial washings found 52 malignancies in the cytological preparations and 43 in the cell blocks. ${ }^{3}$ Four of the "malignant" cell blocks were negative for malignancy on cytology. We did not examine any bronchial washing cell blocks in our study.

The dominance of cytokeratin, S-100, and LCA use reflects the importance of cell block immunostaining in distinguishing between carcinoma and melanoma and between carcinoma and lymphoma. These were by far the most common diagnostic dilemmas to be encountered.

One of the principal advantages of immunostaining cell blocks over immunostaining smears is that a large battery of stains can be easily done on the former. This is exemplified by case 41 (fig 3) in which eight different immunostains were used. It would be difficult to make eight spare smears for immunocytochemistry from a single FNA sample.

Another advantage of cell block immunohistochemistry is that it requires no special techniques or equipment and so it may be readily adopted by small laboratories that are able to perform immunohistochemistry on paraffin wax sections of histology specimens but would only occasionally need to immunostain cytological specimens.

Kung et al reviewed some other advantages of cell block immunostaining over immunocytochemistry of unstained or destained sections. ${ }^{1}$ Storage of cell blocks is easier than unstained slides. Freezing is not necessary and there is only minimal deterioration in the antigenicity with time. Destaining cytology slides is labourious and results in the loss of what may be the only conventionally stained cytological material. In addition, the results from immunostaining smears tend to be poor unless the procedure is frequently practised. In particular there tends to be a high level of background staining. This is sometimes due to technical artefact, but even with the best technique heavy background staining often occurs, probably because of non-specific staining of thick clumps of cells and proteinaceous debris. It has been claimed that ThinPrep (Cytyc Corp, Boxborough, Massachusetts, USA) type smears reduce background staining by producing an even deposit of cells that have been washed in buffer. ${ }^{4}$ Our own experience has been that the use of an alkaline phosphatase staining method rather than an immunoperoxidase method greatly reduces background staining in immunostained smears. 


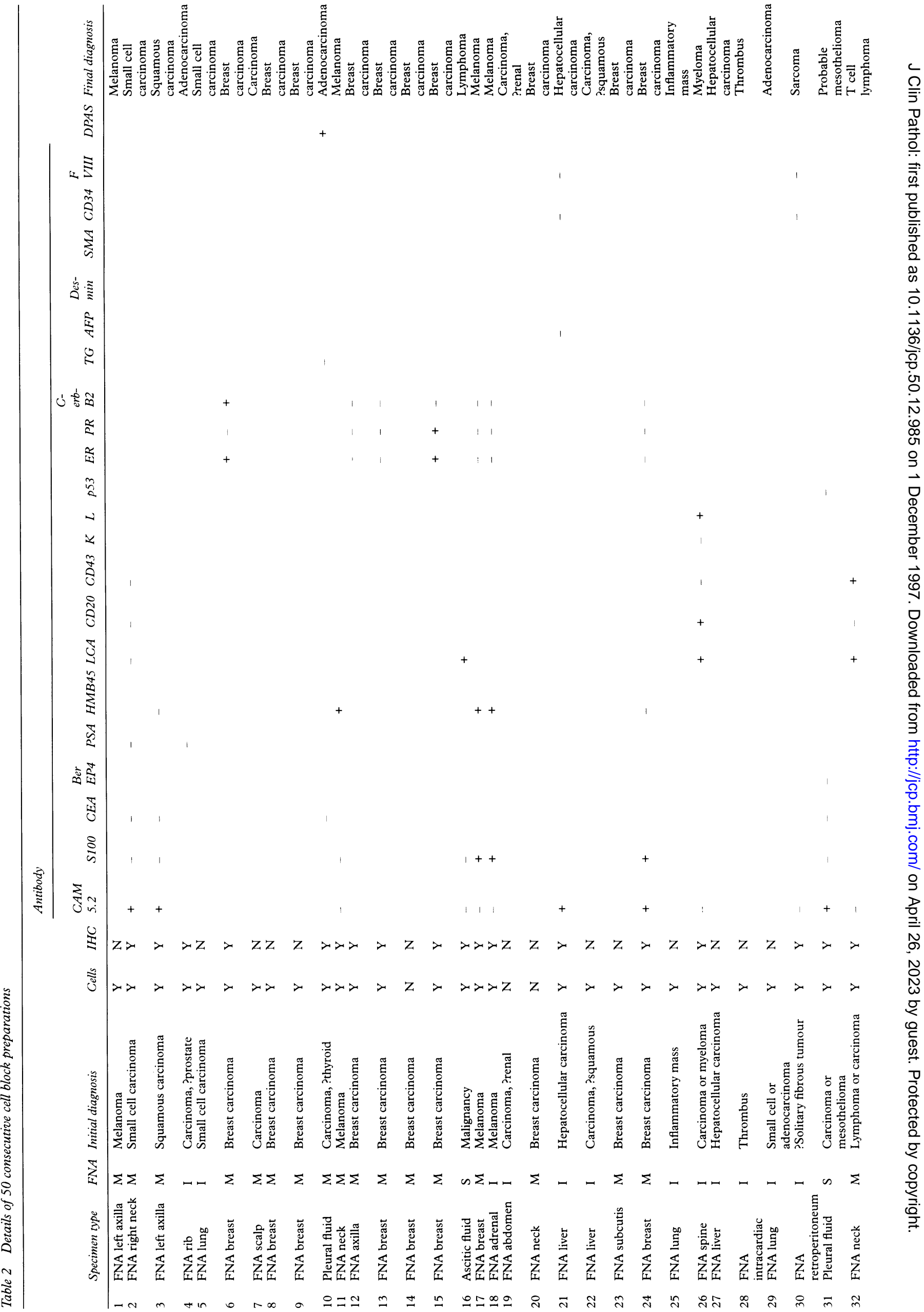




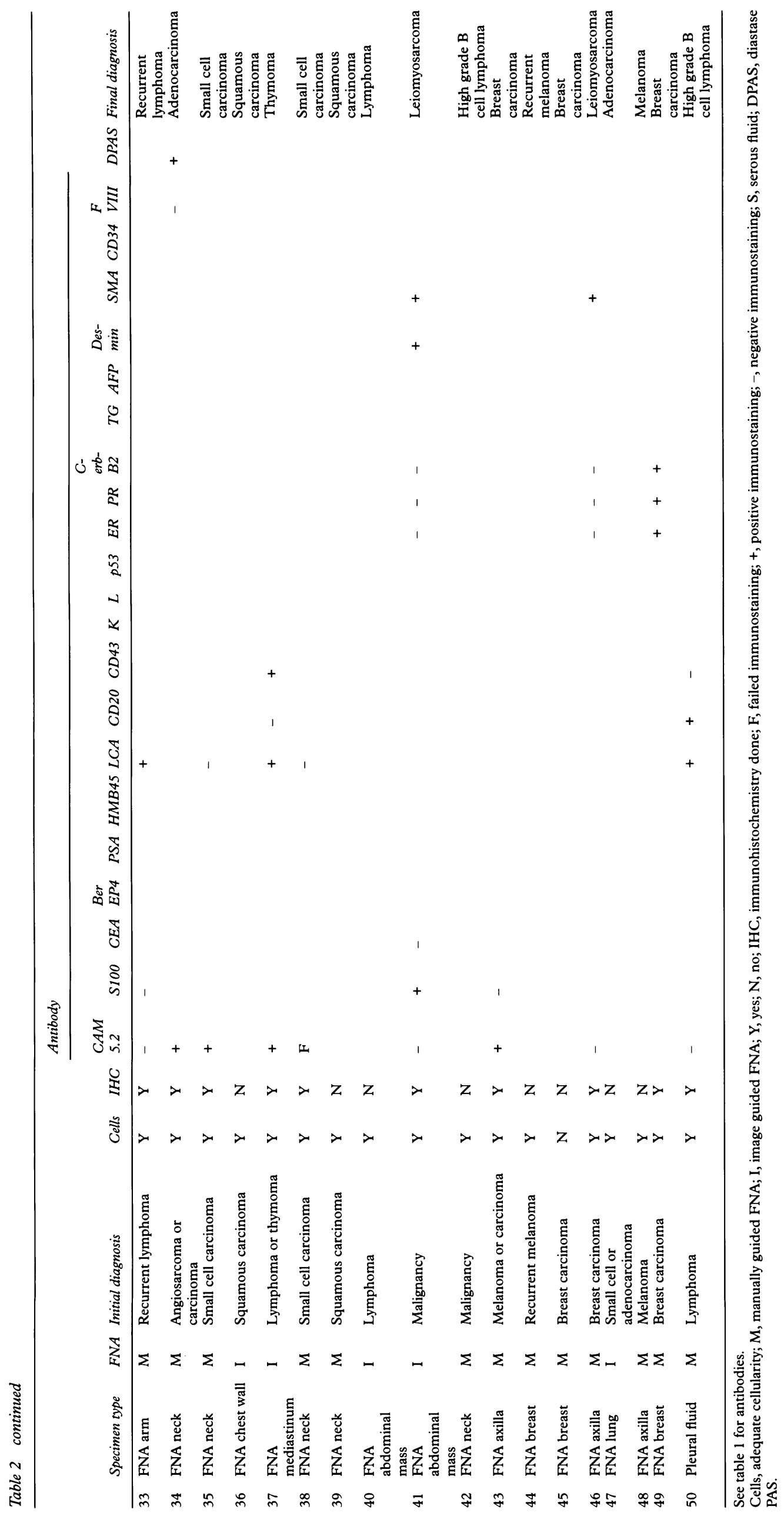


Immunostaining smears does have one notable advantage over cell blocks in that far fewer are needed. This is some times cited as a reason for favouring smear immunostains rather than cell blocks but our study shows that it is almost always possible to obtain sufficient cells from an FNA for cell block immunostaining. A previous study found that 30 of 333 cell blocks had inadequate cellularity. ${ }^{6}$ However, most of these were thyroid cell blocks, which were not examined in our study.

Fluorescent antibodies can be used as immunolabels for unfixed cytospins and for flow cytometry. The effectiveness of these types of labelling in the FNA diagnosis of lymphomas has been examined and these techniques are quite widely used. ${ }^{78}$ They are clearly more effective than cell block immunohistochemistry for characterisation of lymphoid cells, mainly because many lymphoid markers do not survive fixation. However, flow cytometry is not well suited for use with solid tumours as a suspension of single cells is needed. Immunostaining unfixed cytospins of lymphoid lesions has the advantage of requiring far fewer cells than for flow cytometry. However, there is a good deal of technical skill and manual labour involved and it is probably not appropriate for use in centres in which it would be practised only infrequently. In contrast flow cytometry analysis of lymphoid FNAs can be incorporated as a small part of the routine flow cytometry work of a haematology laboratory that consists mainly of bone marrow aspirates and peripheral blood specimens. The high case volume and level of automation makes the analysis cheap and rapid.
In conclusion, our study shows that FNAs can reliably obtain cell blocks with sufficient material to be diagnostically useful. The importance of skilled aspirators is evident and we plan to increase the availability of cytologist aspirators with an increase of 0.7 full time equivalents in the consultant pathologist staff in the laboratory. This should help to cover the annual 1400 FNAs workload that has developed since the introduction of the rapid diagnosis FNA service two years ago. We recognise that there are situations in which a cell block is unlikely to contain sufficient tumour cells. In response, the laboratory has recently introduced an immunocytochemistry method that was previously used by one of the authors in another hospital. ${ }^{5}$

1 Kung ITM, Chan S, Lo ESF. Application of the immunoperoxidase technique to cell block preparations from fine needle aspirates. Acta Cytol 1990;34:297-303.

2 Brown K, Fulbright RK, Avitabile AM, Bashist B. Cytologic analysis in fine-needle aspiration biopsy. Am $\mathcal{F}$ Radiol 1993; 161:629-31.

3 Flint A. Detection of pulmonary neoplasms by bronchial washings. Acta Cytol 1993;37:21-3.

4 Leung SW, Bedard YC. Immunocytochemical staining on ThinPrep processed smears. Modern Pathology 1996;9: 304-6.

5 Mayall F, Heryet A, Manga D, Kriegeskotten A. p53 immunostaining is a highly specific and moderately sensitive marker of malignancy in serous fluid cytology. Cytopathology 1997;8:9-11.

6 Zito FA, Gadaleta CD, Salvatore C, Filotico R, Labriola A, Marzullo A, et al. A modified cell block technique for fine needle aspiration cytology. Acta Cytol 1995;39:93-9.

7 Chernoff WG, Lampe HB, Cramer H, Banerjee D. The potential clinical importance of fine needle aspiration/flow cytometric diagnosis of malignant lymphoma. $\mathcal{F}$ Otolaryngol 1992;21 (suppl 1):1-15.

8 Hanson CA. Fine-needle aspiration and immunophenotyping: a role in diagnostic histopathology. Am f Clin Pathol 1994;101:555-6. 